\title{
Sobre la responsabilidad como criterio de calidad de las intervenciones con varones que ejercen violencia en contextos de pareja
}

\author{
About responsibility as a criterion of quality of interventions with \\ men who commit violence in couples contexts
}

\author{
Gabriel Abarca Brown', Diego Aguirre Alvarado² y \\ Mauricio Carreño Hernández ${ }^{3}$
}

\begin{abstract}
Resumen
El presente artículo tiene por objetivo discutir en torno a la concepción de responsabilidad como criterio de calidad de las intervenciones con varones que ejercen violencia en contextos de pareja, a la luz de los aportes realizados por la sociología de Bourdieu y el psicoanálisis freudo-lacaniano. Se discute sobre la dimensión volitiva asignada al acto violento, por una parte, y la impronta kantiana con la que se concibe el ideal de asunción de responsabilidad, por otra; lo que tendería a desplazar y velar dimensiones que determinan y posicionan a los sujetos en sus relaciones genéricas. Asimismo, se promueve una concepción de responsabilidad amparada dentro de los marcos de la ética del cuidado, como una dimensión prioritaria en el trabajo con varones.
\end{abstract}

Palabras clave: responsabilidad - dominación masculina - violencia en contextos de pareja intervenciones con varones - ética del cuidado.

\begin{abstract}
The present article aims to discuss about the conceptions of responsibility as a criterion of quality of interventions with men that commit violence in couple contexts, at the light of the contributions of Bourdieu's sociology and freudian-lacanian psychoanalysis. It is discussed about volitional dimension assigned to the violent act, on the one hand, and the kantian stamp with which there is conceived the ideal one of assumption of responsibility, on the other; which would tend to displace and ensure dimensions that they determine and position to the subjects in their generic relations. Also, a conception of responsibility covered within the framework of the ethics of care as a priority status in the work with men is promoted.
\end{abstract}

Key words: responsibility - masculine domination - violence in couple contexts - interventions with men - ethics of care.

Fecha de recepción: 14 de mayo de 2012

Fecha de aprobación: 3 de junio de 2014

Psicólogo. Magíster en Psicología Clínica de Adultos. Docente Universidad de Santiago de Chile. Integrante del Laboratorio Transdisciplinar en Prácticas Sociales y Subjetividad (LaPSoS), Universidad de Chile. e-mail: gabriel.abarca@usach.cl

2 Psicólogo. Profesional de la Unidad de Adolescencia del Centro de Salud Dr. Alejandro del Río, Puente Alto. Profesor-Ayudante en la Universidad de Santiago de Chile. e-mail: diegoaguirrea@hotmail.com

3 Psicólogo. Profesional del Programa Adultos del COSAM Colina. Profesor-Ayudante en la Universidad de Santiago de Chile. e-mail: mauricio.carreno.hernandez@gmail.com 


\title{
PROBLEMATIZACIÓN
}

\author{
"...ver la ética del cuidado como una ética \\ que va más allá de una ética de género, \\ verla como una ética para todos. Todos \\ somos igualmente capaces para el cuidado..."
}

Comins (2009)

La visibilidad alcanzada por el problema de la violencia de género en las últimas décadas ha traído consigo la necesidad de contar con instrumentos que permitan comprender, prevenir y promover la modificación de comportamientos que atenten contra la integridad de quienes son y/o han sido objeto de las más variadas transgresiones (Amuchástegui, 2008).

En el ámbito de las relaciones de pareja, específicamente, diversas iniciativas han apuntado a un mayor alcance en la pesquisa, diagnóstico e intervención con varones 4 que cometen actos violentos contra la mujer; con el fin de acceder a una comprensión integral del problema, que no solo considere a quienes han sido afectados por la violencia, sino que también incorpore a quienes llevan a cabo estos actos (Ramírez, 2009).

Organizaciones tanto gubernamentales como no gubernamentales alrededor del mundo, han realizado esfuerzos por incluir a los varones como agentes de cambio en el problema del ejercicio de la violencia, otorgando especial énfasis a la necesidad de fomentar su responsabilidad en dicha realidad. Lo anterior, es constatado por la investigación: "The Man and Gender Equality Policy Project"5, realizada en países como Brasil, México, Chile, Croacia, China, India, Camboya, Sudáfrica, Tanzania, entre otros; al destacar la variedad de medidas adoptadas con el objeto de comprometer a los varones en el fin de la violencia de género (Parker et al., 2010).

El estudio internacional describe experiencias con mayor o menor grado de avance en materia de violencia de pareja. A nivel latinoamericano, para el caso mexicano por ejemplo, Juan Guillermo Figueroa destaca políticas como el "Programa nacional contra la violencia familiar", y la "Ley general de acceso a las mujeres por una vida sin violencia", que han propiciado avances a la hora de abordar la violencia de pareja desde distintos dispositivos, teniendo como próximos desafíos el logro de la participación y responsabilización de los varones. Por otro lado, Francisco Aguayo y Michelle Sadler describen un panorama distinto para el caso chileno. Según revelan, solo algunos gobiernos, amparados en la "Ley de violencia intrafamiliar", han desarrollado programas orientados a la concientización del problema, el tratamiento con varones, y el apoyo

Se utiliza el significante "varones" y no "hombres" para realzar la condición de género de las masculinidades.

Estudio internacional realizado por el "Instituto Promundo"y el "International Center for Research on Woman".

Ley 20.066 del año 2004 que derogó la antigua Ley 19.325 de Violencia Intrafamiliar de 1994.

108 / PUNTO GÉNERO 
a quienes se han visto afectadas. Por lo mismo, realzan la necesidad de contar con instancias y dispositivos de mejor calidad, que sistematicen y visibilicen sus resultados (Parker et al., 2010).

A pesar de las diferentes medidas adoptadas por los países, es posible identificar algunos objetivos y criterios comunes en las variadas formas que han asumido los dispositivos de atención con varones. En sentido amplio, los programas se constituyen como una opción para hacer frente a la violencia de pareja y, potencialmente, mejorar la seguridad y calidad de vida de las mujeres; objetivo que se integra a un proceso mayor de cambios culturales y políticos que abogan por la supresión de las jerarquías entre los géneros, así como las demás formas de violencia tanto a nivel personal como social (Parker et al., 2010; Geldshlager et al., 2010; Bonino, 2004; Welzer-Lang, 1992).

Durante el año 2010 se publicaron los resultados de un catastro de programas para varones que ejercen violencia, conocido como: "Trabajo con Hombres que ejercen Violencia Doméstica en Europa" (WWP)7 Ilevado a cabo entre los años 2006 y 2008. Se investigaron las principales características de 170 programas vigentes en 19 países de la Unión Europea, con el fin de homogeneizar y discutir las metodologías y experiencias encontradas, para posteriormente construir criterios de calidad para las intervenciones. El estudio permitió la realización de una jornada de expertos de la misma organización en Berlín el año 2008, donde se propusieron algunas directrices para un mayor éxito de las intervenciones (Geldshlager et al., 2010).

Uno de los lineamientos promulgados recibe el nombre de "Principios Importantes para el Trabajo con Hombres Agresores". En ellos, se plantea como objetivo que "[los programas] deberán responsabilizar a los hombres con los que trabajan por la violencia que utilizan, y destacar la necesidad de que ellos asuman la responsabilidad por sus comportamientos violentos y las consecuencias de estos". Asimismo, en cuanto a la relación que se establece entre responsabilidad y violencia, el texto apela al "uso de la violencia como una elección", siendo prioritario -como objetivo de la intervención- el reconocimiento del accionar voluntario de la violencia (Geldshlager et al. 2010. p. 189).

Los resultados del proyecto WWP clarifican cómo es que la asunción de responsabilidad es un fin deseado en el trabajo con varones que ejercen violencia en contextos de pareja, siendo considerado como un objetivo transversal al incluirse como criterio mínimo de calidad de las intervenciones; realidad también evidenciable en los manuales de tratamiento latinoamericanos y chilenos, por cierto ${ }^{8}$.

"Work with Perpetrators of Domestic Violence in Europe".

8 En Chile, por ejemplo, el Ministerio de Justicia en sus "Orientaciones técnicas para la intervención con varones que ejercen violencia contra sus parejas en el contexto intrafamiliar" del año 2009, establece como ejes transversales de su intervención: el género, la responsabilización y la motivación al cambio; con la finalidad de proteger a las "mujeres-víctimas" de violencia intrafamiliar por medio del cambio de los comportamientos violentos de sus parejas varones. 
Sobre la responsabilidad como criterio de calidad de las intervenciones con varones que ejercen violencia...

De esta manera, el abordaje comprendería la toma de conciencia de la elección de ejercer violencia, instalando al ejercicio de la misma como un acto volitivo, lo que sitúa a la problemática dentro del campo del libre albedrío, excluyendo con ello otras dimensiones que determinarían al sujeto, a saber: el determinismo psíquico, las condiciones de clase, las relaciones de poder entre los géneros, entre otras. Por lo tanto, la propuesta sobre la responsabilización supondría la objetivación de la violencia sin que necesariamente se incorpore la complejidad del sujeto que la ejecuta, no siendo explícito -por ejemplo- en qué momento de la intervención un sujeto puede o no considerarse responsable, o los mecanismos subyacentes que permitirían dar cuenta de tal responsabilización (Rengifo, 2005).

Es a partir de esta disyuntiva en torno al concepto de responsabilidad donde surgen las interrogantes: ¿a qué tipo de responsabilidad apuntan estas intervenciones con hombres?, ¿cómo entender la asunción de responsabilidad propuesta como estándar de calidad por este tipo de programas?

Frente a los antecedentes anteriormente expuestos, el objetivo de este artículo será discutir sobre la concepción de responsabilidad como criterio de calidad de las intervenciones con varones que ejercen violencia en contextos de pareja, a la luz de los aportes realizados desde la sociología de Bourdieu y el psicoanálisis freudo-lacaniano. Asimismo, se propone una concepción de responsabilidad amparada en la ética del cuidado como una dimensión prioritaria en el trabajo con varones.

Cabe destacar que los autores, en ninguna medida, buscarán llevar a cabo una discusión que tienda a desresponsabilizar de sus acciones a los varones que perpetran actos de violencia en contextos de pareja. Por el contrario, el ejercicio teórico a realizar busca interrogar y al mismo tiempo profundizar en los procesos que articulan y anudan las relaciones de poder y dominación entre los géneros. De esta forma, se busca que la reflexión permita interrogar los procesos de responsabilización a los que apelan dichas intervenciones. Asimismo, el análisis quedará reducido al problema de la asunción de responsabilidad como criterio de calidad de los programas que trabajan con hombres que ejercen violencia en contextos de parejas heterosexuales, ya que el argumento que orienta este artículo nace a partir del proyecto europeo WWP, anteriormente citado.

\section{PERSPECTIVAS EN TORNO A LA RESPONSABILIDAD}

Desde el racionalismo filosófico constructor de la modernidad, se ha sostenido que el fundamento de la responsabilidad moral se asocia al reconocimiento ante la propia conciencia y la sociedad de la autoría de los actos y su determinación electiva. Dentro de esta tradición, Immanuel Kant, en el siglo XIX, se consolidó como uno de los grandes fundadores del debate moderno en torno a la relación entre moral y subjetividad. Sus planteamientos abogaban por la primacía de una razón pura universal que hacía posible renunciar a los motivos singulares, en nombre de un imperativo moral abstracto. Dicho imperativo fijaba la aprobación y desaprobación de todo el repertorio conductual posible. En este sentido, el "deber" está en función de un juicio 
lógico y razonable a priori, que no depende de una certeza sensible (Greiser, 2008; Rengifo, 2005; Comins, 2003).

Sin embargo, a fines del siglo XIX, Sigmund Freud marcó un giro respecto de los postulados kantianos al trasladar el imperativo moral hacia la singularidad del sujeto. Por medio del concepto de superyó, el padre del psicoanálisis fundó una instancia psíquica que dio cuenta de la moral introyectada en el aparato psíquico. Estos planteamientos permitieron establecer una crítica al reduccionismo racionalista con la instalación de una dimensión singular en la relación que cada sujeto sostiene con la Ley (Greiser, 2008).

De este modo, las teorizaciones freudianas en torno al aparato psíquico otorgaron particular relevancia a las posiciones subjetivas que ocupa el sujeto a lo largo de su historia. Con esto, el foco ético se desplazó desde los principios universales de la razón, hacia la historia del sujeto y sus determinantes. A partir de Freud, el sujeto no solo es responsable de sus actos, sino que también del deseo que lo configura; de la posición como sujeto de la cultura; y de los anclajes inconscientes que lo determinan?

Al respecto, Marta Gerez (1993) señala que la responsabilidad instituida por los postulados psicoanalíticos sientan las bases para lo que ella denomina "culpa simbólica", es decir, la consecuencia existencial -y por tanto ineludible- de ocupar un lugar dentro de la estructura social; lugar que marcará, al mismo tiempo, una deuda en el sujeto.

Lo anterior difiere de un "sentimiento de culpa" o de un "arrepentimiento" declarado por el sujeto, ya que, en tanto formación de la conciencia, la figura del "arrepentido" denuncia sus faltas de manera dislocada debido al descentramiento que introduce lo inconsciente en la subjetividad. Es a esto, lo que Gerez (1993) Ilama "culpa imaginaria". Este concepto se sustenta en el modelo freudiano (2009a) "mala acción-arrepentimientomala acción", donde el arrepentimiento supone la necesidad de hacer inocente al culpable, lo que da lugar a la repetición de los actos/faltas. Como es evidenciable, el arrepentimiento sería en principio opuesto a la responsabilización, puesto que no busca el conocimiento de las singularidades históricas del sujeto, sino que un perdón inmediato que mitigue la angustia, y permita continuar ejerciendo la transgresión (Gerez, 2010).

En consecuencia, a mayor "culpa imaginaria" menor responsabilidad y viceversa. Freud (2009b) desechó al "sentimiento de culpa por arrepentimiento" y la "necesidad de castigo" como indicadores clínicos válidos de dilucidación teórica, en la medida en

$9 \quad$ Al respecto, Foucault consideraba al psicoanálisis como una contraciencia, conflictiva con el proyecto iluminista moderno, signándola como la ciencia del inconsciente, en tanto conduce hacia aquello fuera del hombre que hace posible saber lo que se da o lo que se escapa a su consciencia: el inconsciente. Desde este lugar criticará dos tradiciones filosóficas dominantes en occidente -por un lado, la idea del sujeto trascendental, motor de la historia; y por otro, el concepto de subjetividad psicológica- destacando la necesidad de realizar un tratamiento histórico, ético y político del sujeto con el objeto de hacer visibles los mecanismos de sujeción y subjetivación eventualmente velados por componente ideológicos. 
que no es posible articular una clínica del arrepentimiento y la purgación. Contrario a ello, emerge la verosimilitud de la clínica de la culpa inconsciente o simbólica; aquella que resulta de la condena interior de la conciencia moral introyectada, en tanto búsqueda histórica y singular en lo propio del sujeto. En palabras de Rengifo (2005)..."Ia responsabilidad del sujeto es, en suma, la responsabilidad del bien decir, lo que se deduce del respeto a la singularidad del sujeto, al deseo que lo habita, y al derecho al enigma que introduce el inconsciente en la cultura" (pp. 154-155).

Por lo tanto, la presencia de la culpa no es indicadora fundamental de una transgresión, sino del deseo, de modo tal que no es posible realizar desde esta óptica una lectura lineal y mecánica entre los movimientos subjetivos de culpa y responsabilidad. En este sentido, para la responsabilidad la culpa es un paso preliminar necesario, pero no suficiente. El sujeto puede mantenerse eternamente en su culpabilidad sin nunca hacerse responsable de ella, siendo esta encrucijada la que demanda una reparación en el lazo social, llevando a cabo la acción no solo para sí, sino también para el otro (Greiser, 2008).

\section{HACIA UNA ÉTICA DEL CUIDADO}

Radicalmente opuesta a los desarrollos emanados por Freud a principios del siglo $X X$, es la tradición asumida para el estudio del desarrollo moral en occidente. Según señalan Alonso y Fombuena (2006), las indagaciones permiten observar cómo es que ha trascendido la "buena voluntad" como ley rectora, instalándose en reglas universales de regulación de la conducta de los sujetos. Del mismo modo, De Benoist (1997) agrega que dicha fórmula caracterizó la constitución del derecho moderno, donde lo central fue el establecimiento de derechos inherentes a todos los individuos considerados aisladamente, reconvirtiendo así los deseos y expectativas personales en normas que sintetizaron un concepto universal de lo jurídico, excluyendo el contexto y las condiciones de aplicabilidad.

Es en esta tradición anclada en la conciencia, donde se inscribe el difundido modelo de desarrollo moral de Lawrence Kohlberg. Según el psicólogo estadounidense, sería por medio de un tránsito universal e invariante por fases sucesivas de desarrollo cognitivo, donde se tramitaría la definición moral de cada sujeto; entendida como la discriminación correcta entre lo bueno y lo malo, a partir de juicios racionales que moldean conductas que encuentran correspondencia en leyes abstractas y universales de comportamiento, las que, con independencia del contexto, cumplen el criterio de lo justo. Por ello, a este modelo de desarrollo moral se le llamó: "la ética de la justicia".

Las investigaciones de Kohlberg enunciaban -sesgadamente- que los varones cumplían mejor los postulados de la justicia, ya que poseían un comportamiento moral más adecuado que el de las mujeres que propugnaban el valor de la igualdad, considerado un logro moral de inferior estima. De esta forma, bajo la óptica del desarrollo moral de Kohlberg, la responsabilidad fue situada en referencia a un razonamiento normativo, que se define como imparcial al buscar la justicia de las acciones humanas en una universalidad de aplicación indiferenciada (Carosio, 2009). 
A partir de estos planteamientos surgieron múltiples críticas -principalmente desde la perspectiva feminista- sobre el modo de entender el desarrollo moral. Los postulados calificaban a la ética de Kohlberg como una teoría eminentemente individualista, racional, fría y abstracta, en la medida en que presenta la referencia exclusiva de un individuo-tipo, que excluye la injerencia de factores situacionales y de diferencias interindividuales (Alonso y Fombuena, 2006); anulando así, muchos otros determinantes de la subjetividad: afectividad, género, clase social, vínculos primarios, entre otros.

Del mismo modo, Camps (1990) agrega que una ética de la justicia es imperfecta, pues al focalizar la atención en necesidades generales, se producen leyes intransigentes que uniformizan a través del castigo. En definitiva, la motivación es la evitación de "acciones incorrectas", y no la orientación hacia una lógica de la responsabilidad que plantee una respuesta; una reparación.

En contraposición a los hallazgos de Kohlberg, la ética del cuidado -como parte del discurso feminista- plantea de base una responsabilidad específica, que ubica en el primer plano al otro, al necesitado, al allegado. La ética del cuidado parte de las necesidades del otro con independencia de un criterio previo de verdad, sea este bueno o malo (Alonso y Fombuena, 2006).

Para plantearlo en otros términos, la moralidad como compromiso deriva de la certeza de que el bienestar, e incluso la supervivencia, requieren algo más que autonomía, primacía del individuo, reconocimiento de derechos, justicia, etc. La responsabilidad significa respuesta, extensión y no limitación de la acción. Implica así un acto de cuidado y atención, más que un freno a la agresión (López, 2004; Gilligan, 1986). Vale decir, en palabras de Camps (1998) "... no es el individuo autónomo, autolegislador, quien toma la iniciativa y establece reglas, sino la interpelación del otro necesitado que exige ser atendido" (p. 76).

Para Carosio (2007), las características de la ética del cuidado mueven el imperativo ético kantiano a una concepción relacional, que se destaca por un juicio más contextual y por una mayor tendencia a ponerse en el lugar del otro particular. La ética del cuidado, asimismo, incorpora la injerencia de los afectos y la amplia gama de variables que intervienen en la situación a juzgar.

El supuesto ético que se deriva desde esta perspectiva para las ciencias sociales, integra un fundamento feminista que se ha configurado como una de sus insignias en cuanto expresa el núcleo de sus planteamientos (Palomar, 2002). Así, el lema "Io personal es político", comanda la lucha por la integración de los mundos privado y público, de lo afectivo y lo racional, de lo íntimo y lo social, de lo teórico y de lo práctico; al promover una valórica contrahegemónica que rompa con la ilusión de control que generan estas dicotomías, hacia la búsqueda de modos de convivencia más libres de prescripciones centradas en lógicas patriarcales de dominación. 
Sobre la responsabilidad como criterio de calidad de las intervenciones con varones que ejercen violencia...

El cuidado entonces, se propone como un valor demandado en lo social, en el sentido de que toda ética debe cimentarse en un estar-con-el-Otro. De esta forma, en lo relativo a la responsabilidad, la ética del cuidado se distanciaría radicalmente de la ética que sostiene y legitima la dominación masculina, en tanto la asunción de responsabilidad trascendería las contingencias individuales. Como refiere Carosio (2009): "El norte del cambio ético será la construcción de una "sociedad del cuidado", no como receta para mujeres sacrificadas, sino como asunto para la transformación social radical (p. 249). Del mismo modo, Fiona Robinson destaca: ". . el poder transformador de la ética del cuidado se extiende más allá del ámbito personal al ámbito político, y de ahí al contexto global de la vida social" (en Comins, 2003. p. 150).

Si bien no es suficiente pensar en la aplicabilidad de una ética universal, ya que sus referencias connotan una ontología individualista y finalmente injusta, tampoco basta con conformarse con una moral excesivamente cotidiana y relacional. En este último caso, no sería sensato sugerir que los códigos interpersonales vayan siempre por sobre la perspectiva de la acción moral, pues plantearían un relativismo que pudiese ser perjudicial, en tanto carecería de una referencia de consenso previo que oriente el actuar (Fascioli, 2010).

Por ello, la principal superación del argumento iniciático kantiano, realizado por el descubrimiento freudiano, por una parte, y la ética feminista del cuidado, por otra, es enunciar que la fuente de las responsabilidades están determinadas fundamentalmente por la presencia del otro, singular, concreto, irrepetible (Bárcena y Mèlich, 2000, en Comins, 2003). Como afirma Camps (1998), "pensar éticamente es pensar en los demás", lo que debe traducirse en una praxis en todos los niveles de la realidad, tanto en términos de justicia, como de cuidado.

\section{DOMINACIÓN MASCULINA Y VIOLENCIA EN LA PAREJA}

Hasta aquí, la violencia en contextos de pareja invita a ser pensada más allá de su reducción al acto agresivo. Necesariamente, implica la comprensión de diversos mecanismos subyacentes - de carácter relacional- que distan de aquella percepción de "evento aislado", y que estarían asociados a pautas de configuración psíquica profundamente ancladas en la subjetividad masculina (Burín y Meler, 2009).

En este sentido, uno de los autores que más han contribuido al entendimiento del papel que juega la cultura patriarcal en la construcción de las masculinidades es Pierre Bourdieu, quien, en su obra "La dominación masculina", sostuvo que el ordenamiento social ratifica mecánica e inmutablemente la supremacía del género masculino por sobre el femenino. Vale decir, no solo de la opresión que los varones pueden ejercen sobre mujeres, sino que también sobre otras masculinidades consideradas subordinadas.

El escenario propuesto por Bourdieu permite una aproximación hacia los efectos que ejerce el patriarcado en el panorama descrito, en específico, cómo es que la dominación social masculina determina una "violencia simbólica" desatada desde la economía de 
los intercambios, generando una síntesis que acecha a los vínculos de pareja entre hombres y mujeres, en una dinámica que va más allá del ejercicio del libre albedrío y la volición de los actos humanos. De esta forma, con el concepto de "violencia simbólica", Bourdieu (2000) no intentaba minimizar el lugar de la violencia física, psicológica, sexual y/o económica entre los géneros, ni justificar o querer disculpar a los varones por dichas acciones. Esa presunción se ampararía en la idea de un entendimiento de la violencia simbólica como expresión "puramente espiritual"10, olvidando los efectos reales de los actos violentos en sus diferentes manifestaciones.

Desde la misma perspectiva, Ana María Fernández (2009) comprende los fundamentos de la subjetivación de los géneros a partir de "dispositivos de desigualación", los que, gracias a su larga tradición histórica, contemplan una dimensión subjetiva que determina no solo la propiedad de los aparatos de discriminación, sino que a la vez permiten la marginalidad, la exclusión, la represión y el establecimiento de sistemas de argumentos que justifican y proponen lo que es justo y conveniente desigualar.

A raíz de esto, es que el orden masculino parece no recurrir significativamente a una renovación frecuente de discursos que autovaliden su ejercicio de poder, ya que con relativa independencia de las transformaciones culturales y su impacto en las categorías y procesos de subjetivación -todo aquello evidenciado por los movimientos feministas, con la consecutiva protesta y la concientización del dominio ejercido- su posición continúa imponiéndose a sí misma como evidente y universal. Es decir, una estructura de dominación que reproduce sus condiciones de posibilidad constantemente.

En efecto, es en el marco de la dominación masculina amparada en la estructura patriarcal, donde la violencia de género se expresa en sus distintas formas sobre lo femenino (Hernández et al. 2007; Scott, 1997). En palabras de Fernández (2009), la dominación masculina "...crea las condiciones para alguna expropiación de bienes y derechos", sea en un plano material, simbólico, civil, erótico, etc.

La misma autora ejemplifica esta proposición argumentando que una mujer, ante un acto de violencia física, no solo sufre los efectos de los golpes en su cuerpo y toda la agresión verbal concomitante, sino que al mismo tiempo, es "despojada de toda libertad personal. Pierde progresivamente en la dinámica del terror en que queda inscripta su vida diaria, hasta las mínimas independencias tanto en sus relaciones laborales, sociales, afectivas como en sus decisiones personales, eróticas y económicas" (p.15).

Dicho panorama, ampliamente observado en contextos de violencia de pareja, se vincula según Bourdieu al entendimiento del amor como una "dominación aceptada", desconocida como tal, pero reconocida y exhibida en la pasión feliz o desgraciada (Palomar, 2002), donde la organización social que encarna la pareja, es paradigma

10 Sentencia ocupada por Bourdieu para tomar distancia de cualquier concepción materialista primaria que desconozca lo traumático de la violencia en su dimensión real. 
Sobre la responsabilidad como criterio de calidad de las intervenciones con varones que ejercen violencia...

de la sobreidentificada jerarquía de géneros; siendo la violencia lo que se inscribe primeramente en su constitución (Hernández, et al. 2007).

En la lógica de Bourdieu, la violencia simbólica es capaz incluso de transformar las relaciones de dominación y de sumisión en relaciones afectivas y de amor, invisibilizando al mismo tiempo las asimetrías de poder que regulan el intercambio entre los géneros.

\section{DETERMINACIÓN PSÍQUICA DE LA VIOLENCIA EN CONTEXTOS DE PAREJA}

La violencia ejercida en contextos de pareja se asienta, como se ha desarrollado hasta ahora, sobre una estructura amplia de dispositivos de desigualación que conducen al ejercicio de un poder que tiende al despojo de bienes sociales, simbólicos y subjetivos de quien es objeto de la violencia. Tal consideración provee un marco que permite adentrarse en la reflexión del fenómeno considerando el efecto de la desubjetivación de la pareja en el vínculo amoroso.

El ejercicio de poder y dominación del género masculino inscribe una dinámica del terror, en tanto la violencia logra acceder hasta en los más mínimos espacios de la vida femenina. Así, por un proceso de apropiación/despojo de bienes materiales y simbólicos, la violencia se consolida como un instrumento que -concretamenteconsigue la sumisión y cosificación del otro (Fernández, 2009).

Este ejercicio coercitivo de apropiación de los bienes femeninos resulta de un proceso de objetivación de la mujer; la que ve arrasado el dominio y control de su subjetividad, al ser rebajada a existir como mero objeto de dominación. La violencia ejercida sobre el cuerpo de la mujer se constituye como la prolongación de una violencia discursiva que aplasta con la injuria y los insultos; nominaciones imaginarias que le impiden la emergencia y el despliegue, en tanto sujeto, de sus derechos (Rivadero, 2008).

Por su parte, Spivacow (2011) argumenta que la violencia debe ser discutida a partir de un sustrato vincular de interacción y retroalimentación entre los partenaires, trascendiendo la habitual presentación de superficie, es decir, la ilusión de una personificación inmutable bifurcada en la víctima y el victimario. De este modo, las intervenciones podrían abordar los mecanismos que permiten la emergencia de la violencia de una manera amplia, superando las variables individuales de tipo caracterológicas y/o las etiquetas psicopatológicas tradicionales (Aceituno y Walker, 1995).

En consecuencia, precisar los determinantes de la violencia de pareja implica considerar que el vínculo amoroso constituye un plus, un algo más que las individualidades en escena, asumiendo la forma de un todo que es más que la suma de sus partes, en la medida en que es en la intimidad cotidiana, uno de los espacios donde se reactualizan los contenidos conscientes e inconscientes que configuran el mapa de lo permitido y lo prohibido, lo facilitado y lo obstaculizado; reflejo de un orden social supeditado a las normatividades y reglas genéricas (Spivacow, 2011). 
Dichas reglas genéricas toman a los varones por medio de las premisas de la masculinidad hegemónica (Connell, 1997), que prescribe mandatos que determinan un gran espectro de subjetivación. En este sentido, Fernández (2009) representa esta dinámica con los siguientes cuestionamientos, intentando graficar un marco identificable desde donde contextualizar la emergencia de la violencia al interior de la pareja:

\begin{abstract}
"¿Por qué razón el potenciamiento de las mujeres suele servisto como una amenaza para tantos hombres? ¿Por qué los éxitos públicos de sus mujeres suelen empequeñecerlos subjetivamente? ¿Por qué tantos hombres prefieren la prisión del proveedor antes que la paridad política en las relaciones amorosas? ¿Por qué sería tranquilizador suponer que sus mujeres están con ellos porque son su sostén material? antes que imaginar que ellas, resueltas personalmente sus cuestiones económicas, estarían a su lado solo por amor, deseo, respeto, ternura, etc. (p. 70).
\end{abstract}

Sobre este mismo punto recae el análisis realizado por Aceituno y Pereda (1995), al señalar que la violencia emerge en un momento fundante asociado a una historia no problematizada hasta entonces en el contexto vincular, viéndose comprometida la armonía idealizada de la pareja. Los celos, el embarazo o el nacimiento de un hijo son ejemplos que nuclean una dimensión que suele contextualizar el inicio de la violencia, al activar cambios en las posiciones subjetivas al interior de la pareja que no logran metabolizarse simbólicamente, al tener un anclaje en el escenario fantasmático de la relación amorosa.

Así, la violencia pasa a representar la reactualización de la problemática en torno al poder en la pareja, donde la imposibilidad del intercambio abre paso a la angustia y al colapso ante la ruptura del equilibrio vincular. Desde lo masculino, tal característica aparecería vinculada especialmente a un cierto ideal perdido que vendría a poner en tela de juicio el poder asignado a la representación de sí (Aceituno y Pereda, 1995).

Desde esta perspectiva, es posible encontrar en los albores del psicoanálisis freudiano -específicamente en los trabajos de "Tres ensayos de teoría psicosexual" de 1905, y las tres "Contribuciones a la psicología del amor", escritas entre 1910 y 1918- la despoetización del amor, por medio de la instalación de un trasfondo que revela la confluencia de corrientes tanto tiernas como agresivas en el objeto amoroso. Vale decir, la ambivalencia de los sentimientos recae sobre el objeto amado. Por ejemplo, para el caso de la elección de objeto, Miller (2010) señala que dicho momento carecería en lo absoluto de ser un acto basado en el libre albedrío y la voluntad, sino que más bien operaría bajo la lógica de una determinación inconsciente.

Por su parte, Aguiar (1989) destaca que en la elección de la pareja, la idealización conlleva el registro del no reconocimiento, es decir, la primacía paradójica entre la fantasía y la realidad; aquello que es donde no está. Este mecanismo conlleva el potencial de la violencia en tanto lo idealizado, al sustentarse desde un "lugar otro" (no como correspondencia imaginaria de amor a la pareja), corre el riesgo inevitable de desidealizarse, de desilusionar. 
Sobre la responsabilidad como criterio de calidad de las intervenciones con varones que ejercen violencia...

Los desencuentros entre los partenaires en el vínculo amoroso son develados por Freud al desarticular la imagen mítica e ideal de la fusión que el amor romántico lograría en la pareja, lo que Lacan posteriormente inmortalizará con la sentencia: "no hay relación sexual", con el fin de enfatizar la imposibilidad del encuentro en la pareja.

En efecto, Assoun (2006) enfatizará la imposibilidad de que el amor y la satisfacción sexual logren un cauce común, argumentando que en tal desencuentro opera el registro de la pasión. Para el autor, lo pasional juega un papel trascendental en la relación amorosa, emergiendo como un actor principal en tal entramado, siendo capaz incluso de subvertir hasta al amor mismo. Un "más allá" del amor, que se tornó incompatible con la felicidad, ya que está supeditada a la esfera de lo pulsional, de la angustia y el exceso.

Así, ese inestable equilibrio entre sujeto, sexualidad y filiación presente en el vínculo de pareja supone en el caso de la violencia, un atolladero en donde fantasías e idealizaciones generan el terreno propicio para la emergencia de una demanda por parte de uno/a o ambos partenaires, lo cual se muestra incongruente a la ley de intercambios y las posibilidades subjetivas de cada sujeto (Rivadero, 2008). Esta encrucijada se solucionaría en "la vida o la muerte", en "el otro o yo", en "el todo o nada", donde no hay lugar para los matices y la relativización, sino solo al advenimiento de la pasión en tanto exceso y violencia. Una significativa paradoja determina que la pasión amorosa sea tanto el colmo del amor en la pareja como el instrumento de su propia subversión (Assoun, 2006).

\section{DISCUSIÓN}

Durante la década de los ochenta comienza a emerger una serie de esfuerzos enfocados al tratamiento con varones que ejercen violencia en contextos de pareja, los que se materializaron en la organización, sistematización e implementación de dispositivos de atención que permitieran la erradicación o disminución de la violencia mediante la concientización y responsabilización de los actos de violencia.

Para lograr esta tarea, las intervenciones optaron por hacer confluir diferentes discursos: jurídico, clínico y educacional. Así, por medio de variados dispositivos, se objetivaron las condiciones de posibilidad para el reconocimiento en lo social del "hombre agresor" como agente de un acto transgresor, instituyéndose una apertura para la transformación de las relaciones genéricas.

Es en este marco donde adquieren relevancia los diversos catastros realizados alrededor del mundo, en especial el citado "Trabajo con Hombres que ejercen Violencia Doméstica en Europa" (WWP), ya que permiten obtener una panorámica de los estándares mínimos de calidad que se han construido en la corta historia de trabajo con varones que ejercen violencia. Como se ha mencionado, el estudio instala como criterio de calidad el logro de la asunción de responsabilidad por parte de los varones del acto violento (Geldshlager et al., 2010). 
Si bien dicho rastreo aún no se ha realizado en todos los países de Latinoamérica (Viveros, 2007), como es el caso de Chile (Parker et al., 2010), es posible identificar en intervenciones a nivel nacional concepciones y objetivos similares: la voluntariedad y elección del acto violento, y la responsabilización consciente del mismo (Abarca, Carvajal, Cifuentes, 2012). Es decir, una comprensión de la violencia que se reduce al acto agresivo y que se desentiende de otras dimensiones que determinan al sujeto.

A partir de la constatación en torno de la responsabilización como criterio de calidad de las intervenciones, y del acto violento en su dimensión puramente volitiva, se evidencia una concepción de responsabilidad amparada en un modelo centrado fundamentalmente en la primacía de la razón, la consciencia y la voluntad. La suposición principal que estructura sujeto-acto-responsabilidad, se basaría en la idea de la autoconsciencia y la libre elección en función de un juicio racional que instala a la violencia como una elección en último término. Este supuesto esencial actuaría como un determinante transversal en la conceptualización del objeto de intervención -el hombre que ejerce violencia-; el acto dañino a ser erradicado y transformado -la violencia-; sus causas y determinantes; y las estrategias que permitirían su intervención, es decir, sus metodologías, las prácticas y las tecnologías presentes en el dispositivo de atención.

Si la materialización del acto violento se desprendiera del razonamiento libre y soberano del sujeto, solo bastaría para su responsabilización el reconocimiento y visibilización de tal elección. Vale decir, solo bastaría con el "arrepentimiento" o, en palabras de Gerez, con la expresión de la "culpa imaginaria" del varón para que el interventor o su entorno legitimen la responsabilización de sus actos, sin que necesariamente el sujeto haya accedido a un trabajo de elaboración de sus determinantes, y de reparación del daño ejercido.

Más aún, el reconocimiento e identificación de su lugar de agente -la captura en su propia imagen- sería la que el dispositivo reflejaría a partir de las constataciones de las causas, el hecho y sus consecuencias.

Desde la concepción de responsabilidad basada en la ética de la justicia, el sujeto sería el único y exclusivo responsable de la violencia, sin que quepa, en su discurso, la inserción de cualquier otro tipo de elemento contextual, relacional y/o histórico. En última instancia, el fenómeno queda confinado al ámbito estrictamente individual, desplazando sus determinantes a una coyuntura histórica particularizada y desmembrada.

Dicho tratamiento de la violencia y de la responsabilidad, desde una crítica foucaultiana, se enmarcaría dentro de dos tradiciones filosóficas: por un lado, la idea de sujeto trascendental, motor racional de la historia; y por otro, el concepto de subjetividad psicológica, en tanto autor y amo. Tales elementos de la tradición filosófica moderna son potencialmente ideológicos en tanto obnubilan espacios de la subjetividad, determinan puntos de visibilización y enunciación, al velar los diferentes mecanismos de sujeción y subjetivación. En este sentido, tal crítica destituye la soberanía constituyente del sujeto (Castro, 2008). 
Sobre la responsabilidad como criterio de calidad de las intervenciones con varones que ejercen violencia...

Asumir una concepción de responsabilidad y acto violento anclada en las lógicas de la autodeterminación, además impedirían reconocer, en el ámbito de pareja, aquellos determinantes tendientes a regular los intercambios. En este sentido, destacan los argumentos desde la perspectiva psicoanalítica al señalar que la discusión debe superar la mera superficie, y atravesar la dicotomía y personificación víctima/victimario, para instalar el sustrato vincular propio de la relación amorosa en el análisis, en el cual se contemplen aspectos no problematizados de la historia de la relación de pareja.

Por tanto, el vínculo amoroso se constituye como un plus en el que se reactualiza el contraste entre fantasía y realidad, posibilitando desencuentros tendientes a romper con el equilibrio vincular de la intimidad cotidiana. Es este plus, este "más allá" del amor -en palabras de Assoun- el escenario donde los partenaires Ilevan a cabo el acto violento, enmarcado en la lógica pasional capaz de subvertir hasta los más tiernos sentimientos.

En efecto, la violencia en contextos de pareja es posibilitada -entre otras condiciones- por el vínculo amoroso; instancia en la que se reeditan las dinámicas propias de la cultura patriarcal, y hacen viables modos de subjetivación violentos. Es en esa "dominación aceptada" del amor, como señala Bourdieu, donde las masculinidades, por medio de los "dispositivos de desigualación", legitiman aquellos actos de violencia tendientes a la expropiación de bienes simbólicos y el posicionamiento de la mujer en el lugar de objeto de dominación.

Hasta aquí, es evidenciable que la concepción de asunción de responsabilidad del acto violento se enmarca dentro de la tradición filosófica de la autodeterminación, velando aquellas dimensiones sociohistórico-culturales inscritas y reproducidas en las relaciones entre los sujetos. Es decir, una responsabilidad sostenida en el argumento del sujeto consciente. Realizar un giro en la conceptualización implicaría que más que llevar a cabo un reconocimiento en la imagen del accionar violento -"soy responsable de mis actos"-, el sujeto debería tender a develar/elaborar aquellos elementos invisibilizados determinantes de la violencia. Por tanto, no bastaría con el reconocimiento del ejercicio del acto de violencia, sino que, además, debería integrarse al análisis que aquel acto violento responde a la validación y legitimación de dispositivos de dominación reproducidos en los distintos espacios, en especial, en lo íntimo de la relación de pareja.

Desde estas coordenadas, la responsabilidad podría ser entendida, para los efectos de las intervenciones con varones, a partir de los fundamentos de la ética del cuidado, con el fin de problematizar su lugar como criterio de calidad de las intervenciones, por una parte, y como una posibilidad de concebir la violencia de pareja en su dimensión realmente relacional, por otra.

Lo anterior, supone comprender que los efectos de la violencia no solo deben asociarse a una falta moral, es decir, a la desobediencia de los significados sociales que regulan un comportamiento exigido como condición cultural, sino que también deben interpretarse desde una óptica feminista circunscrita al realce del otro involucrado 
-la mujer/víctima- como objeto hacia el cual dirigir los lineamientos de reparación, instalando lo central de su posición, como figura y no como fondo de un proceso de responsabilización.

Situar el foco en quien sufrió violencia, no implica restar valor a las obligaciones que se demandan a quien la ejerce, sino que por el contrario, permite superar la relación establecida incorporando protagónicamente durante la intervención al otro subyugado en el terreno psíquico de quien lleva a cabo el acto violento.

La adopción de una ética del cuidado como respuesta al llamado a incorporar el legado feminista en los programas de atención aludidos, politiza el postulado de Ana María Fernández relativo a la restitución/reapropiación de bienes simbólicos y derechos expropiados a las víctimas, al darle aplicabilidad concreta en las intervenciones. Es decir, la posibilidad de reparar quien encarnó el lugar de víctima, por una parte, y de la asunción de responsabilidad en el varón en tanto compensa el lazo social, por otra.

La propuesta de una ética del cuidado no solo hace referencia a la simbolización relacional relativa a un acto violento propiamente tal, sino también considera su dimensión simbólica, es decir, las condiciones estructurales de diferenciación y desigualación subjetiva que le antecedieron, le fundamentaron y permitieron su emergencia.

Se plantea de esta forma, que el proceso de responsabilización conlleva necesariamente el reconocimiento de las posiciones subjetivas que asumen varones y mujeres, y los efectos concomitantes en su vinculación de pareja, lo que instala al problema no solo en la dimensión temporal de la historia de la pareja, sino que también fija su campo de acción hacia la proyección de un futuro más justo e igualitario.

En síntesis, sostener que la asunción de responsabilidad se tiña de una ética del cuidado implica no solo hacerse cargo del daño cometido en lo real del cuerpo de la pareja y la consecutiva restitución de los bienes simbólicos expropiados, sino también considera un reconocimiento de las formas nocivas de las prescripciones de género, con el fin de modificarlas en lo cotidiano, en la repartición de las tareas domésticas, en la flexibilización de las configuraciones psíquicas asentadas en el mandato de la masculinidad hegemónica.

Finalmente, la reflexión propuesta no se restringe a la adecuación exclusiva de una ética del cuidado, sino que solo enfatiza y promueve su aplicación. De esta forma, se invita a consignar las condiciones sociales de producción de la moral a la cual apelan los procesos de responsabilidad entendidos desde una óptica civil y penal, en tanto, retomando a Kant, considerar lo moral como consenso universal, determinaría una responsabilidad que en su proceso de asunción subjetiva, integraría a la estructura "universal" de dominación masculina; razón por la cual el fin propuesto desde los programas de tratamiento, procedería en oposición a la equidad y el bienestar del otro, al respetar un código formado desde la base jerárquica de los géneros. 
Sobre la responsabilidad como criterio de calidad de las intervenciones con varones que ejercen violencia...

La base patriarcal en la que se sustenta la concepción de responsabilidad amparada en una ética de la justicia, promovería la aplicación de una responsabilidad que explícitamente omite una conexión con el otro violentado, y la subyugación histórica de lo femenino y sus significados atribuidos. La propuesta explicitada en este artículo supone utilizar uno de aquellos significados -la responsabilidad- y situarlo como metodología central de cambio. "Lo importante no es solo la respuesta concreta [...] sino el cuestionamiento de la naturaleza de las relaciones sociales normales en un intento de entender los procesos de exclusión y marginalización que crean la necesidad de la intervención humanitaria" (Robinson, 1999, p.144 en Comins, 2009 p. 169).

\section{BIBLIOGRAFÍA}

Abarca, Gabriel; Carvajal, Carla; Cifuentes, Ángela (2012):"Análisis de las concepciones de masculinidad a la base de la intervención en hombres propuesta por el plan de seguridad pública del Ministerio del Interior", en Rev. de Psicología. Universidad de Chile. Vol, 21, Nº 1, pp. 159-184. Santiago.

Aceituno, Roberto; Walker, Cristián (1995): "Estudio exploratorio-descriptivo en hombres que ejercen violencia conyugal, consultantes al Centro de Violencia de la I. Municipalidad de Santiago", en Rev. Chilena de Psicología. Vol, 16. № 2, pp. 21-33. Santiago.

Aceituno, Roberto; Pereda, Viviana (1995): Condiciones Subjetivas Vinculadas a la Violencia Conyugal. Un estudio descriptivo. En Aceituno, Roberto (comp): Violencia, Familia y Cultura. Pp. 129-139. Universidad Diego Portales.

Aguiar, Elina (1989): Violencia social. Su repercusión en la pareja. Buenos Aires: Asamblea Permanente por los Derechos Humanos.

Alonso, Rosario; Fombuena, Josefa (2006):"La ética de la justicia y la ética de los cuidados", en Revista Portularia, Vol. VI, Nº 1. Pp. 95-107. Universidad de Huelva.

Amuchástegui, Ana (2008): "La verdad... yo no creía que era violento. Cuerpo emocional y subjetivación en un programa reeducativo para hombres violentos", en Parrini (Coord): Los Contornos del alma, los límites del cuerpo: género, corporalidad y subjetivación.) Pp.155-181. México: Unam.

Assoun, Paul-Laurent (2006): La pareja inconsciente. Buenos Aires: Letra Viva.

Bourdieu, Pierre (2000): La dominación masculina. Buenos Aires: Anagrama. (1991): El sentido práctico. Madrid: Taurus.

Bonino, Luis (2004): "Masculinidades, salud y sistema sanitario: El caso de la violencia masculina", en C. Ruiz Jarabo y P. Blanco: La violencia contra las mujeres: Prevención y detección (pp. 71-80), Madrid: Díaz de Santos. 
Burin, Mabel; Meler, Irene (2009): Varones: Género y subjetividad masculina. Buenos Aires: Librería de mujeres.

Camargo, Luis (2005): Encrucijadas del Campo psi-Jurídico. Buenos Aires: Letra Viva.

Castro, Rodrigo (2008): Foucault y el cuidado de la libertad. Ética para un rostro de arena. Santiago: Lom.

Comins, Irene (2009): Filosofía del cuidar. Una propuesta coeducativa para la paz. Barcelona: Icaria.

Comins, Irene (2003): La ética del cuidado como educación para la paz. Tesis doctoral. Castellón: Universidad Jaume I.

Camps, Victoria (1998): El siglo de las mujeres. Madrid: Cátedra.

Camps, Victoria (1990): Virtudes Públicas. Madrid: Espasa-Calpe.

Connell, Robert (1997): "La organización social de la masculinidad”, en Valdés y Olavarría (Eds.). Masculinidad/es. Poder y crisis. Pp.31-48. Chile. Isis-Flacso.

Carosio, Alba (2007): "Ética para la utopía. Más allá de la justicia", en Revista Cubana de Filosofía, n 9. Instituto de Filosofía. La Habana.

Carosio, Alba (2009): "Feminismo latinoamericano: imperativo ético para emancipación", en Revista Género y globalización. 1a ed. Pp. 229-252. Buenos Aires. Consejo Latinoamericano de Ciencias Sociales: CLACSO.

De Benoist, Alain (1997): "Cómo se ha roto el lazo social", en Revista Hespérides n 14, [On line]. Disponible en: http://foster.20megsfree.com/index_es.htm [Recuperado el 11 de marzo del 2012].

Fascioli, Ana (2010): "Ética del cuidado y ética de la justicia en la teoría moral de Carol Gilligan", en Revista ACTIO no 12. Uruguay. Universidad de la República.

Fernández, Ana María (2009): Las lógicas sexuales: amor, política y violencias. Buenos Aires: Nueva Visión.

Freud, Sigmund (2009a): Dostoievsky y el parricidio. En Obras completas. Volumen XXI. Buenos Aires: Amorrortu.

Freud, Sigmund (2009b): El malestar en la cultura. En Obras completas Volumen XXI. Buenos Aires: Amorrortu.

Garda, Roberto (2009): Intervención Integral con Hombres que ejercen Violencia Contra su Pareja. Análisis de Modelos y Lineamientos de Trabajo. México: Hombres por la Equidad. 
Sobre la responsabilidad como criterio de calidad de las intervenciones con varones que ejercen violencia...

Geldschläger, Heinrich et al. (2010): "Programas Europeos de Intervención para Hombres que ejercen Violencia de Género: Panorámica y Criterios de Calidad", en Rev. Intervención Psicosocia/ Vol. 19, №2, pp. 181-190. Colegio Oficial de Psicólogos de Madrid.

Gerez, Marta (1993): Las voces del superyó. Buenos Aires. Manantial.

-- (2010): Intimidación y registros de la culpa. Psicoanálisis y el hospital № 38: Responsabilidad e imputabilidad. Buenos Aires.

Gilligan, Carol (1986): La moral y la teoría. Psicología del desarrollo femenino. México: Fondo de Cultura Económica.

Greiser, Irene (2008): Delito y transgresión. Un abordaje psicoanalítico de la relación del sujeto con la ley. Buenos Aires: Grama.

Hernández, Fernando et al. (2007): "El papel de la violencia en el aprendizaje de las masculinidades", en Revista de Educación, No 342. Pp. 103-125. México.

López, Teresa (2004): "Ética de la diferencia", en Román Reyes (2004): Diccionario Crítico de Ciencias Sociales. [on line] Pub. Electrónica, Universidad Complutense: Madrid. Disponible en http://www.ucm.es/info/eurotheo/diccionario, [Recuperado el 22 de Marzo del 2012].

Miller, Jacques-Alain (2010): Los divinos detalles. Buenos Aires: Paidós

Palomar, Cristina (2002): "Pierre Bourdieu en ocho perspectivas. Un homenaje", en Revista Dossier N²4. Universidad de Guadalajara.

Parker, Gary et al. (2010): What men have to do with it: Public policies to promote gender equality. Washington D.C. Promundo and International Center for Research on Woman.

Ramírez, Ramiro (2009): "Hombres Agresores: la otra cara de la violencia intrafamiliar: Un abordaje desde el Modelo Integrativo Supraparadigmático", en Rev. Actualizaciones en Psicoterapia Integrativa Vol. I, Pp. 59-67. Santiago: Instituto Chileno de Psicoterapia Integrativa.

Rengifo, Francisco (2005): "La responsabilidad del sujeto", en Revista Desde el jardín de Freud. Vol. V Pp.144-155. Bogotá: Universidad Nacional de Colombia.

Rivadero, Stella (2008): Fracasos del amor. Impedimentos del deseo y enclave del Goce. Buenos Aires: Letra Viva.

Scott, Joan (1997): "El género, una categoría útil para el análisis histórico", en M. Lamas (Ed.) El género: la construcción cultural de la diferencia sexual (pp. 265-302). México: Porrúa-Pueg. 
Spivacow, Miguel (2011): La pareja en conflicto. Aportes psicoanalíticos. Buenos Aires: Paidós.

Viveros, Mara (1997). "Teorías feministas y estudios sobre varones y masculinidades. Dilemas y desafíos reciente", en Rev. La manzana de la discordia. Año 2, № 4. Pp. 25-36. Colombia.

Welzer-Lang, Daniel (1992): "La violence masculine domestique et les hommes violents", en Places du père, violence et paternité. Lyon: Champs. Presses Universitaires de Lyon. 